\title{
Redes sociales, vínculos familiares y poder político en el Río de la Plata en el siglo XIX. Los Posse en Tucumán, 1820-1870
}

\author{
Social networks, family ties and political power in the Río de la Plata in the \\ 19th century. The Posse in Tucumán, 1820-1870
}

\author{
Francisco Bolsi \\ Instituto Superior de Estudios Sociales, (Universidad Nacional de Tucumán) \\ Consejo Nacional de Investigaciones Científicas y Técnicas, Argentina \\ franciscobolsi@hotmail.com
}

\section{Resumen}

El estudio de la familia desde la perspectiva de las redes sociales es relativamente nuevo en el campo historiográfico argentino, sobre todo, en el ámbito regional y local. Por este motivo, el propósito de esta investigación fue analizar la configuración de las redes sociales y vínculos familiares por parte de los Posse entre 1820-1870 con la finalidad de indagar en la configuración de la elite y el papel desempeñado por esta familia en el ámbito local. Para ello, se relevaron diferentes fuentes -Sección Protocolos, Judicial Civil, Administrativa de Hacienda, Compilación Ordenada de Leyes, Boletines genealógicos- que se encuentran en el repositorio documental del Archivo Histórico de Tucumán. A partir de este análisis, se comprobó las estrategias implementadas por la familia Posse, tanto desde sus relaciones de parentesco como sus vínculos informales que le permitieron detentar el poder en varias ocasiones en Tucumán, en el siglo XIX.

\section{Palabras claves}

Familia, Redes Sociales, Parentesco, Matrimonios, Política.

\begin{abstract}
The study of the family from the perspective of social networks is relatively new in the Argentine historiography field, especially at regional and local level. For this reason, the purpose of this research was to analyze the configuration of social networks and family ties by the Posse between 1820-1870 in order to investigate the configuration of the elite and the role played by this family at the local level. For this purpose, different sources section protocols, genealogical newsletters, Civil Judicial, administrative finance, ranked compilation of laws - which are found in the document repository of the historical archive of Tucumán is relieved. From this analysis, found the strategies implemented by the Posse family, both from their kinship relationships as informal ties that allowed her to hold power in several occasions in Tucuman, in the 19th century.
\end{abstract}

\section{Keywords}

Family, Social networking, Kinship, Marriage, Political. 


\section{Francisco Bolsi}

\section{Introducción}

A partir del cuestionamiento de los grandes paradigmas historiográficos dominantes hasta la década de 1980, la utilización del análisis inductivo de la sociedad en relación a los actores sociales se reveló como una nueva línea de investigación que aportó un novedoso enfoque al estudio de las relaciones entre los individuos. ${ }^{1}$ En este sentido, a partir de estos aportes se experimentaron cambios significativos en la visión acerca del sistema político y del ejercicio de poder en América Latina desde fines del siglo XVIII al siglo XX. Gracias a estas contribuciones, en la actualidad, se comprobó que las luchas por los espacios de poder eran más complejas de lo que se creía. Por lo tanto, esta nueva forma de analizar a los actores sociales permitió la identificación de las configuraciones reales y las relaciones efectivas entre los individuos para reconstruir sus redes sociales. ${ }^{2}$

Esta nueva perspectiva de análisis tomó en cuenta los múltiples espacios y formas de poder que se manifestaron en Hispanoamérica. Por este motivo, los aportes al estudio de las redes sociales efectuados por Bertrand, Ponce Leiva y Amadori permitieron un análisis reflexivo del rol que jugaron las redes de poder y la forma en que fue utilizado este concepto por sociólogos e historiadores. ${ }^{3}$

En este sentido, la producción historiográfica argentina referida a las redes sociales y el poder se abocó, por un lado a realizar estudios generales vinculados con las dinámicas de las elites entre el período colonial y la construcción del Estado-Nación y por otro lado, a indagar desde perspectivas micro históricas la

\footnotetext{
${ }^{1}$ La bibliografía en América Latina es sumamente extensa: Federico Requena Santos. "El concepto de red social”. Reis; no 48, Octubre - Diciembre. Madrid, 1989; págs. 137-152. Joseph Galaskiewicz, y Stanley Wasserman. "Análisis de redes sociales. Conceptos, métodos y direcciones para los años 90”. Sociological Methods \& Research; Vol. 22. Madrid, 1993; págs. 137-152. Andrea González Ripolli Navarro. "Vínculos y redes de poder entre Madrid y la Habana: Francisco Arrango y Parreño (17651837), ideólogo y mediador". Revista de Indias; Departamento de Historia de América "Fernández de Oviedo"; Vol. LXI, mayo - agosto, n²22. Madrid, 2001; págs. 291-305. Michel Bertrand. "De la familia a la red de sociabilidad". Revista mexicana de sociología; Vol. 61, n. 2. México, 1999; págs. 107-135. "En busca de una identidad social: redes familiares y elite colonial en tiempos de crisis". Anuario de Estudios Bolivarianos; Universidad Simón Bolívar, Venezuela, 1999, págs. 97-118. Gabriela Dalla Corte. "La consistencia de la red social: el Ferrocarril Oeste Santafesino entre la Argentina pampeana y el Chaco paraguayo, 1880-1890”. Pilar García Jordán, (ed.), Dinámicas de poder local en América Latina, siglos XIX y XX. Barcelona, TEIAA-UBE, 2009; págs.13-54.

2 Zacarías Moutoukias. "Redes sociales, comportamiento empresario y movilidad social en una economía de no mercado (el Río de la Plata en la segunda mitad del siglo XVIII)”. Blanca Zeberio, María Berj y Hernán Otero. Reproducción social y sistemas de herencia en una perspectiva comparada. Europa y los países nuevos (Siglos XVIII al XX). Buenos Aires, UNCPBA, Instituto de Estudios Históricos y Sociales, 1996; págs. 63-81. José María Imicoz. "Actores, redes, procesos: reflexiones para una historia más global”. Historia, Revista da Faculdade de Letras; III Serie, Vol. 5. Portugal, 2004; págs. 115-140.

3 Michel Bertrand..., Op. Cit. Pilar Ponce Leiva y Arrigo Amadori. "Redes sociales y ejercicio del poder en la América Hispánica: consideraciones teóricas y propuestas de análisis". Revista Complutense de Historia de América; Vol. 34. Barcelona, 2008; págs. 15-42.
} 


\section{Redes sociales, vínculos familiares y poder político}

composición de las elites provinciales y la lógica de distribución del poder. ${ }^{4}$ En el ámbito tucumano, los historiadores locales indagaron la construcción del poder desde la perspectiva de la historia política y la configuración de las elites en el siglo XIX y en ciertos casos, esa aproximación al objeto de estudio, se realizó desde la historia de familia y el papel central que desempeñó el parentesco como elemento cohesionador de la elite en la construcción del poder. ${ }^{5}$

Uno de los estudios pioneros desde la perspectiva de las redes sociales en el ámbito local fue la tesis doctoral (inédita) de Iramain, quien estudió la conformación de las comunidades políticas entre las provincias de Tucumán, Catamarca y Santiago del Estero, entre 1810-1838. ${ }^{6}$ El autor indagó la construcción de las redes sociales en un contexto de transformaciones políticas entre el período revolucionario y el control de la región por el caudillo riojano Facundo Quiroga, quien logra mediar en la relación conflictiva que existía entre las elites de las tres provincias. Por este motivo, recurrió al concepto de red social con la finalidad de analizar la configuración de las comunidades políticas y el papel que desempeñaron las redes a la hora de conseguir acuerdos tendientes a construir o asegurar el orden político.

Sin embargo, el análisis desde la perspectiva de las redes sociales en el ámbito local es en la actualidad escaso. Por este motivo, el propósito de esta investigación fue analizar la configuración de las redes sociales y vínculos familiares por parte de los Posse entre 1820-1870 con la finalidad de indagar en la configuración de la elite y el papel desempeñado por esta familia en el ámbito local.

Cabe aclarar los motivos de la elección de los Posse. Esta familia resultó un caso paradigmático en la historiografía tucumana a partir de su participación en la política local y nacional en el período de construcción del Estado-Nación argentino. De la misma manera, fueron propietarios de ingenios azucareros en Tucumán y se vincularon con familias de la elite local y nacional.

Asimismo, cabe aclarar que la intención de este trabajo no es cuantificar a partir de la teoría de grafos, los vínculos de los Posse, sino más bien indagar en las

\footnotetext{
${ }^{4}$ La bibliografía es mucho más amplia, sólo que para esta cita se tomaron aquellos trabajos significativos para la elaboración del presente artículo: José Mateo. Población, parentesco y red social en la frontera. Lobos (provincia de Buenos Aires) en el siglo XIX. Mar del Plata. Universidad Nacional de Mar del Plata, GIHRR, 2001. Claudia Herrera. Elites y poder en Argentina y España en la segunda mitad del siglo XIX. Madrid. Tesis de Doctorado (inédita), Universidad Complutense de Madrid, 2003. En línea: http://biblioteca.ucm.es/tesis/ghi/ucm-t26882.pdf /fecha de acceso: $3 / 9 / 2015$.

${ }^{5}$ Florencia Gutiérrez. Prácticas políticas en Tucumán en la década de 1860: El partido Posse. Tucumán. Tesis de Licenciatura (inédita). Facultad de Filosofía y Letras. UNT. 1998. María Celia Bravo y Daniel Campi. "Elite y poder en Tucumán, Argentina, segunda mitad del siglo XIX". Secuencias; $\mathrm{n}^{\circ}$ 47, mayo -agosto. México, 2003; págs. 75-104. Cristina López. Los dueños de la tierra. Economía, sociedad y poder en Tucumán (1770-1820). Tucumán, Facultad de Filosofía y Letras, UNT, 2003.

6 Pablo Iramain. La construcción de comunidades políticas en el Río de la Plata: Tucumán, Catamarca y Santiago del Estero 1810-1838. La Plata. (en línea). Trabajo final de posgrado, Universidad Nacional de la Plata, Facultad de Humanidades y Ciencias de la Educación, 2010 Disponible en: www.fuentesmemoria.fahce.unlp.edu.ar/tesis/te.445/te445pdf
} 


\section{Francisco Bolsi}

características de esas relaciones buscando un sentido explicativo, lo que daría cuenta de qué manera el contexto político, económico y social condicionó los vínculos familiares internamente y cómo los Posse construyeron una red que permitió su permanencia en el seno de la elite tucumana.

Para la elaboración de este trabajo se utilizó diversas fuentes. En el Archivo Histórico de Tucumán (AHT en adelante) se relevó el Boletín Genealógico con la finalidad de analizar el parentesco formal e informal de la familia Posse. La Sección Administrativa (SA en adelante), las Actas de la Sala de Representantes y la Compilación Ordenada de Leyes con la finalidad de identificar a los miembros de la elite que desempeñaron los cargos.

\section{La familia y la red social}

La historia de familia desde 1970 aportó un análisis significativo para comprender la dinámica del parentesco y la configuración de las elites hispanoamericanas en la construcción del Estado-Nación. ${ }^{7}$ Sin embargo, el estudio de la familia desde la perspectiva social es un campo historiográfico reciente. El mismo aportó una categoría analítica a la historia social, al comprender la familia como un punto de articulación con el mundo social y su interpretación desde una perspectiva interdisciplinaria generó un renovado interés en esta línea de investigación.

Con la finalidad de analizar a la familia los investigadores recurrieron al concepto de red social para explicar relaciones formales y no formales que los actores sociales y las familias establecen en su entorno. A partir de esta idea, la familia cobra nuevamente vida y es comprendida dentro de un entorno social, en una red virtual en donde los individuos se interrelacionan a partir de vínculos no sólo basados en el parentesco y la consanguinidad sino en otras formas como el compadrazgo, el paisanaje, la solidaridad y la voluntad, entre otras variables.

\footnotetext{
7 La historia de familia es una corriente historiográfica que se inició en los años 70’ con Peter Laslett y la escuela de Cambridge. Posteriormente, la escuela de los Annales realizó sus aportes en esta temática. Véase: Peter Laslett. "Introducción al estudio de la familia". Londres; Cambridge Group for the History of Population and Social Structure; 1972. Linda Levin. Politics and Parentela in Paraiba - Brasil. A case of family - based oligarchy. Princeton; Princeton University Press, 1987. Philipe Aries. El niño y la vida familiar en el antiguo régimen. Madrid; Taurus, 1992. Michel Anderson. Aproximaciones a la historia de la familia occidental (1500-1914). Madrid; Siglo XXI, 1988. George Duby y Philipe Aries. Historia de la vida privada. Del renacimiento a la ilustración. Madrid, Taurus, Vol. 3, 1989. Pilar Gonzalbo Aizpuru y Cecilia Rabell. La familia en el mundo iberoamericano. México; UNAM, 1994. Familia y vida privada en la historia de Iberoamérica. México; UNAM, 1996. David Kertzer y Marzio Barbagli (comp.). Historia de la familia europea Vol.1: La vida familiar a principios de la Era Moderna (1500-1789). Barcelona; Paídos, 2002. Historia de la familia europea Vol. 2: la vida familiar desde la Revolución Francesa hasta la Primera Guerra Mundial (1789-1913). Barcelona, Paidos, 2003. Historia de la familia europea Vol. III: la vida familiar en el siglo XX. Barcelona; Paidos, 2004. Jaime, Contreras Contreras (editor). Familia, poderes, instituciones y conflictos. Murcia; Universidad de Murcia, 2011.
} 


\section{Redes sociales, vínculos familiares y poder político}

La teoría de las redes sociales es deudora de diversas corrientes de pensamiento y de ciencias como la antropología, la sociología, la psicología y la matemática. A partir de los años setenta y ochenta, se produjeron avances significativos en la elaboración de estudios de las redes sociales y sobre todo la publicación de la revista Social Networks aportó al análisis de las familias desde esta perspectiva historiográfica. ${ }^{8}$ Scott fue uno de los pioneros que planteó los orígenes históricos de este concepto con la publicación de Social Networks Analysis en 1991.9

En este sentido, se entiende como red a un núcleo determinado de personas que se encuentran interrelacionadas por vínculos -relacionados con la consanguinidad-y no específicos, que trascienden el parentesco y que representan valores e intereses que adscriben a la red. Moutoukias, hizo referencia a esta cuestión al considerar que las redes que construyen los individuos se desenvuelven dentro de un marco normativo, pero en la mayoría de las ocasiones su accionar está más influenciado por objetivos personales, sus capacidades y la reciprocidad entre sus miembros estaba condicionada por los buenos resultados obtenidos. ${ }^{10}$

Esta conceptualización se transformó en el eje a partir del cual se estudió la dinámica de la red social y de parentesco que estructuraron los Posse con la finalidad de explicar las estrategias que implementaron en el período en estudio.

A fin de aportar una mayor comprensión del proceso, en los párrafos a continuación, se realizó una breve síntesis del origen de esta familia y su establecimiento en Tucumán.

\section{La red social y parental de la primera generación de la familia Posse}

En el siglo XVIII, la situación económica de la ciudad de San Miguel de Tucumán era favorable debido a su ubicación como intermediaria en el eje Potosí Buenos Aires. De acuerdo con López, la región del Tucumán se caracterizó por su producción ganadera destinada a dos mercados: como ganado en pie que se transportaba hacia las provincias altoperuanas (especialmente a Tarija y Cinti) y como productos derivados (cueros, suelas, grasa, sebo), orientados a los mercados del Litoral. Complementaban la producción local otros bienes como los pellones, el arroz, las maderas, los muebles, las carretas, que se dirigían a la capital del virreinato y zonas aledañas. Desde Tucumán se enviaba el ganado, los pellones y los productos de reexportación (como la yerba y el azúcar) a los mercados del Alto Perú. A cambio de sebo, grasa y quesos se obtenía el metálico y productos manufacturados como los textiles, los sombreros y las mantas. Hacia el Litoral y el puerto de Buenos Aires se destinaban los cueros curtidos, el arroz, las maderas y

\footnotetext{
8 Joseph Galaskiewicz y Stanley Wasserman. “Análisis de redes sociales...”, Op. Cit, pág. 3-22.

9 John Scott. Social Network Analysis. Londres; Newbury Park, 1991.

10 Zacarías Moutoukias. "Familia patriarcal o redes sociales: Balance de una imagen de la estratificación social”. Anuario del IEHS; n 15. Buenos Aires, 2000; págs. 110-130.
} 


\section{Francisco Bolsi}

las carretas. En la ciudad portuaria los comerciantes tucumanos adquirían los "efectos de Castilla", la yerba, el azúcar y las manufacturas que no se producían en la jurisdicción y saldaban las cuentas con plata adquirida en los mercados altoperuano o en la misma capital del Virreinato. ${ }^{11}$

Los comerciantes locales atendían dos mercados. Uno vinculado con la importación de productos -que en el siglo XVIII se incrementó sensiblemente de acuerdo a diversos historiadores- consistente en la importación de efectos de la tierra y efectos de Castilla de bienes que no se producían en la región. ${ }^{12}$

En este escenario económico favorable, Manuel Posse, comerciante peninsular se estableció en Tucumán en 1779. En el ámbito local, las familias de la elite poseían una composición determinada por diferentes variables que tenía en algunas ocasiones como eje la institución familiar y en otras, a personas que pertenecían al círculo extra familiar que se situaba en determinados espacios de poder. Sin embargo en el contexto de las Reformas Borbónicas algunas familias reformularon sus estrategias de reproducción social con el propósito de atravesar, sin sobresaltos, el proceso de transformaciones de la elite a fines del siglo XVIII. ${ }^{13}$

En este contexto de cambios y conflictos internos, se insertaron los comerciantes peninsulares que traían consigo no sólo capitales sino también estrechos vínculos de parentesco, paisanaje y una aceitada red de relaciones con los comerciantes porteños, como fue el caso de los hermanos Manuel y Gerardo Posse. ${ }^{14}$ Manuel se radicó en Tucumán, mientras que su hermano Gerardo, se estableció en Buenos Aires, constituyendo entre ambos una red mercantil que se consolidó con el correr de los años.

Manuel al momento de su establecimiento contaba con un patrimonio cercano a los 14.310 pesos, hecho que lo transformaba en uno de los comerciantes recién llegados con mayor capital en la ciudad. ${ }^{15}$ Manuel integró el grupo de comerciantes que representaban al Consulado de Comercio de Buenos Aires que se insertaron en Tucumán y que contaban con fuertes lazos mercantiles con los principales importadores de efectos de Castilla en la plaza porteña. ${ }^{16}$ Por este

\footnotetext{
${ }^{11}$ Cristina López. Los dueños de la tierra..., Op.Cit, pág. 194.

${ }^{12}$ Los principales productos de importación eran los algodones y lienzos del Alto Perú, yerba de Paraguay, Azúcar de Jujuy y Río de Janeiro, aguardientes y vino de la zona de Cuyo, añil de Chile y Perú, entre otros bienes. Cristina, López. "Comercio de exportación de la jurisdicción de San Miguel de Tucumán: circuitos comerciales y especialización productiva, 1785-1810". Tucumán, 1992.

${ }^{13}$ A partir de la expulsión de los jesuitas, se generó una división de la elite, entre quienes fueron los encargados de llevar a cabo esta medida ordenada por la corona -el sector pro borbónico- y aquellos vecinos que integraban la elite tradicional y que se manifestó en contra de la ordenanza real. Véase: María Lelia García Calderón. "Las disputas por el poder en San Miguel de Tucumán a partir de la expulsión de los jesuitas". Cristina López (comp.). Identidades, representación y poder entre el Antiguo Régimen y la Revolución: Tucumán, 1750-1850. Rosario; Prohistoria, 2009; pág. 25. ${ }^{14}$ Ana María Bascary. Familia y vida cotidiana a fines de la colonia. Tucumán, Facultad de Filosofía y Letras - UPO, 1999; pág. 66.

${ }^{15}$ AHT, Sección Protocolos, Serie A, 1792, f. 173.

${ }^{16}$ Entre los comerciantes que se instalaron en Tucumán, se encontraba José Ignacio Garmendia, José Antonio Álvarez de Condarco, Salvador Alberdi, Cayetano Rodríguez, entre otros. Gabriela, Tío Vallejo. "La "buena administración de justicia" y la autonomía del cabildo. Tucumán, 1770-1820".
} 


\section{Redes sociales, vínculos familiares y poder político}

motivo, estableció vínculos económicos con comerciantes del ámbito local y capitalizó estas relaciones contrayendo matrimonio en 1783 con Águeda Tejerina y Domínguez, quien era hija de Fermín Vicente Tejerina y Barreda y Teresa Domínguez. ${ }^{17}$ El padre de Águeda fue arrendatario de la Sisa en 1764 y recusado como Alcalde de Segundo voto en 1767 y como Gobernador de Armas en 1776, de profesión comerciante. ${ }^{18}$ Fruto del enlace matrimonial entre Manuel Posse y Águeda nacieron siete hijos -seis varones y una mujer- quienes ampliaron la red de parentesco de los Posse vinculándose con otras familias de la elite local. ${ }^{19}$

Este enlace matrimonial, evidencia las normas y costumbres que regían en la elite tucumana del período tardo colonial, donde las familias recurrían a su capital social en tanto elemento nodal del intercambio de contraprestaciones. Las mismas se materializaron en los matrimonios de las descendientes de la elite con estos comerciantes peninsulares que poseían no sólo un capital económico sino político y simbólico. ${ }^{20}$ Esto no resultó una cuestión menor, debido a que la elite local a fines del siglo XVIII cerró filas y estrechó lazos por medio de matrimonios endogámicos, situación que demostró - de acuerdo con Bascary- que sólo se reclutaban determinados peninsulares. ${ }^{21}$ En este sentido, el enlace matrimonial de Posse da cuenta de su capital económico y relacional, hecho que lo transformó en un actor significativo para ingresar a la elite local.

La primera década del siglo XIX marcó el inicio de las uniones matrimoniales de los hijos del peninsular, quienes capitalizaron las relaciones previamente efectuadas por su padre con diversas familias de la elite tucumana. Los apellidos que se incorporaron a la red parental pertenecían en algunos casos a linajes que provenían de tiempos de la conquista, mientras que otros, integraban el grupo de migrantes del período de las Reformas Borbónicas.

El primero en casarse fue José Víctor Posse que contrajo matrimonio con Tomasa Pereira y Araóz, hija del prominente español Manuel Antonio Pereira

Boletín del Instituto de Historia Argentina y Americana "Dr. Emilio Ravignani”; n 18. Buenos Aires, 1998; pág. 42.

17 Los padres de Fermín Texerina y Barreda fueron Francisco Texerina y Barreda y Laurencia García, naturales de Sevilla. De acuerdo con García Calderón, Texerina integró el grupo de funcionarios borbónicos que conformó la Junta de Temporalidades, encargada de la venta de la tierra de los jesuitas, luego de su expulsión. La Ordenanza Real generó una división interna en la élite, entre el sector tradicional pro jesuita y el sector pro borbónico. Véase: María Lelia García Calderón. "Las disputas por el poder...”, Op. Cit., pág. 26

18 Las recusaciones en dos oportunidades de Fermín, se debieron a la puja por el poder entre los dos sectores de la élite enfrentados por la expulsión de los jesuitas. AHT, Sección Administrativa, Vol. 6, f. 35, 36, 37 y 38. AHT, Sección Judicial Civil, caja 25, exp. 29, f. 184 (v), caja 23, exp. 1, f. 2. 19 José Víctor (1785/1852), Simón (1789-1838), Vicente (1796/1884), María del Rosario (1794), Luis (1797/1847), Felipe (1806/30-1878), Francisco Posse (se desconoce cualquier otro dato al respecto de su persona). José María Posse. Los Posse. El espíritu de un clan. Buenos Aires, Sudamericana, 1996; págs. 41-48.

20 Posse participó en el cabildo de la ciudad ocupando diferentes cargos. Defensor de Menores (1787), Síndico Procurador de la ciudad (1788), Alcalde de Barrio (1793), Tesorero de Bulas (1801), Alcalde Ordinario de $1^{\text {o }}$ Voto (1804). Celia Avellaneda de Ibarreche, María del Carmen Del C. Clessi y Jorge Corominas. "Autoridades del cabildo, justicia y regimiento - tercera parte (17791824)”. Centro de Estudios Genealógicos, Vol. 5. Tucumán, 2007; págs. 170, 180, 187, 194, 196.

21 Ana María Bascary. Familia y vida cotidiana..., Op. Cit, págs.185. 


\section{Francisco Bolsi}

vinculado con el Consulado de Buenos Aires motivo por el cual ocupó el cargo de Diputado de Comercio por Tucumán en diversas ocasiones y de Magdalena Aranguren Aráoz emparentada con Bernabé Araóz, quien fuera elegido como el primer gobernador propietario de la provincia de Tucumán entre 1814-1817 y presidente fundador de la República del Tucumán entre 1820-1821.22 La consumación de este enlace evidenció, por un lado la búsqueda de fortalecer lazos entre connacionales, debido a que Manuel Antonio Pereira y Manuel Posse emigraron en el mismo momento, estaban vinculados al Consulado de Comercio de Buenos Aires y desempeñaron la función de Diputados de Comercio. Por otro lado, marcó el acercamiento a la tradicional familia Araóz -cuyos orígenes se remontaban a los viejos troncos coloniales- que pertenecía al grupo anti borbónico de acuerdo con García Calderón. ${ }^{23}$ En este sentido, eso evidencia la reformulación de alianzas al interior de la elite que intentaba adaptarse al nuevo escenario político y social que deparaba la década de 1810.

Vicente Posse contrajo matrimonio con Sabina Talavera Olivera en la iglesia matriz de la ciudad de Santiago del Estero. ${ }^{24}$ Sabina era hija de José de Talavera, destacado comerciante y militar de extensa carrera que participó en la reconquista de Buenos Aires de 1806. Llegó al grado de coronel y fue hermano de la prestigiosa Tercera Orden de la Penitencia en Santiago del Estero y de Mauricia Olivera, perteneciente a una de las familias provenientes de los primeros conquistadores de la región. ${ }^{25}$

La única hija de Manuel Posse -María del Rosario- se casó en 1806 con Roque Pondal y Blanco. ${ }^{26}$ En el censo de 1812, figura con la edad de 28 años y en el padrón de electores de 1818 está registrado con residencia en el Tercer Cuartel de la ciudad -en la zona sur- como europeo endonado de 34 años, casado y de profesión comerciante. ${ }^{27}$ Pondal se desempeñó como Procurador General (1810), Regidor Decano (1821), Alcalde Ordinario de Segundo voto (1822), Juez de 1o Nominación en lo Civil (1826) y Diputado de la Sala de Representantes (182931). ${ }^{28}$ Este matrimonio permitió, por una parte, la inserción social de Roque Pondal en el contexto tucumano y por otra parte, resultó una prueba de los vínculos existentes entre individuos que provenían de la misma región en la Península

\footnotetext{
${ }^{22}$ Aparte de ser designado Diputado de Comercio en varias oportunidades, Manuel Pereira se desempeñó como Teniente Tesorero en 1801. Celia Avellaneda de Ibarreche, María del Carmen Del C. Clessi y Jorge Corominas. “Autoridades del cabildo...”, Op. Cit., pág. 184.

${ }^{23}$ María Lelia García Calderón. “Las disputas por el poder...”, Op. Cit, págs. 2.

${ }^{24}$ Catedral de Santiago del Estero, matrimonios I, sección matrimonios entre españoles, 2o parte, f. 3.

${ }^{25}$ Centro de Estudios Genealógicos de Tucumán, Boletín n ํㅜ 3, año 2003; pág. 7.

${ }^{26}$ Roque Jorge Pondal y Blanco nació en Camariñas en 1783 y se encontraba radicado en la ciudad de San Miguel de Tucumán en los primeros años del siglo XIX. Justino Terán. "Los Pondal. Aportes genealógicos". Centro de Estudios Genealógicos de Tucumán; Vol. 4. Tucumán, 2004; pág. 63.

${ }^{27}$ El término endonado, se refiere que se encuentra registrado como Don en la fuente. AHT, Sección Administrativa, Censo de 1812, f. 203. Luis Marcelo Zelarayán. "Padrón de electores de 1818". Centro de Estudios Genealógicos de Tucumán; Vol. 3. Tucumán, 2003; pág. 234.

${ }^{28}$ Celia Avellaneda de Ibarreche, María del Carmen Del C. Clessi y Jorge Corominas. "Autoridades del cabildo...”, Op. Cit. págs. 192, 204, 206.
} 


\section{Redes sociales, vínculos familiares y poder político}

Ibérica, debido a que el peninsular era originario de la región de Camariñas, ubicada en las inmediaciones de Santa María de Sada lugar de nacimiento de Manuel Posse. Sin embargo, se piensa que existió cierto grado de parentesco, debido a que las madres de ambos eran de apellido Blanco y provenían de la misma región, aunque hasta el momento esto solo es una conjetura.

Tanto Manuel Antonio Pereira -padre de Tomasa- como Roque Pondal mantenían un fluido contacto comercial con Gerardo Posse, quien era el destinatario de los productos exportados por ambos comerciantes a Buenos Aires. $^{29}$ Ambos fueron registrados con la categoría de Don en la contribución voluntaria solicitada en 1806 para enviar dinero y tropas para reconquistar la ciudad de Buenos Aires de la primera invasión inglesa.

En el caso tucumano, la Revolución de Mayo no significó un corte definitivo con el Antiguo Régimen, de acuerdo a la historiografía local. ${ }^{30}$ Se observó que, si bien algunos apellidos en el Cabildo de Tucumán se repitieron, existieron otros nuevos, lo que estuvo directamente relacionado con la forma en que las distintas familias de la elite fueron encontrando su espacio de participación y articulación en la disputa por el poder. ${ }^{31}$ Los cambios no se produjeron de manera violenta luego de iniciada la Revolución- sino de forma paulatina, en un proceso de transferencia del poder de unas familias a otras, e incluso, Manuel integró junto con su yerno Roque Pondal el grupo de vecinos que aceptó la adhesión a la junta revolucionaria de Buenos Aires. ${ }^{32}$

En esta década, se formalizaron las uniones matrimoniales del resto de los hijos de Manuel Posse. Simón Posse contrajo enlace con Josefa Insúa y García. ${ }^{33}$ Su hermano, Francisco se casó con su prima Rudencia Insúa y García, hija de Tomás de Insúa Posse y Rafaela de los Remedios García. ${ }^{34}$

Luis Posse, a diferencia de sus otros hermanos se relacionó con una joven perteneciente a la elite tucumana -Isabel Bores- hija legítima del español Francisco Bores y Carmen Velarde. Bores era uno de los comerciantes más destacados de la ciudad con una capacidad de giro comercial en 1813 de $\$ 16.000 .^{35}$ Felipe Posse, el menor de los hijos de Manuel, fue el primero de los descendientes que contrajo matrimonio con una sobrina, Rafaela Posse Insúa (hija de Simón). ${ }^{36}$

Los matrimonios de la primera generación demostraron las estrategias implementadas por Manuel Posse al momento de unir a sus hijos con familias del

\footnotetext{
${ }^{29}$ Manuel Antonio Pereira efectuó 13 envíos hacía Buenos Aires de los cuales 8 fueron para Posse. En cambio, todas las exportaciones de Pondal se orientaron a través de la red comercial de la familia Posse. AHT, Sección de Comprobantes de Contaduría y Oficios Varios, Cuadernos de Tomas de Razón en los años 1800-1809.

30 Irene García de Saltor. La construcción del espacio político. Tucumán en la primera mitad del siglo XIX. Tucumán, Facultad. de Filosofía y Letras, 2003; pág. 52.

31 Ídem, pág. 53.

32 Documentos Tucumanos. Actas del Cabildo. Tucumán, 1939, págs. 42-43.

33 José María Posse. Los Posse..., Op. Cit, pág. 45.

34 Tomas Insúa Posse se casó en segundas nupcias con Rafaela de los Remedios García. José María Posse. Los Posse..., Op. Cit, pág. 46

35Ídem, pág. 47. AHT, Sección Administrativa, Censo 1813, f. 482.

36 Ídem, pág. 47.
} 


\section{Francisco Bolsi}

medio local y de Buenos Aires. Esta situación evidenció un marcado comportamiento endogámico debido a que todos los enlaces se realizaron con descendientes de españoles peninsulares. De acuerdo con Otero, los migrantes españoles e italianos mantenían pautas similares a sus lugares de origen con la finalidad de reproducir las estrategias familiares en el territorio a donde emigran $^{37}$. Asimismo, se observó, la combinación de enlaces matrimoniales y actividades económicas debido a que todos los integrantes de la red se dedicaban al comercio, algunos de ellos, como Manuel Antonio Pereira y Roque Pondal integraban la nueva elite mercantil que se consolidó a fines del siglo XVIII en el contexto de las Reformas Borbónicas. De la misma manera, las uniones matrimoniales de Simón y Francisco manifestaron dos intenciones, por un lado la concentración del patrimonio familiar hacia el interior de la familia Posse en Tucumán y por otro lado, el reforzamiento de la red comercial de los Posse, quienes mantuvieron un lazo directo con sus primos, los Posse Insúa de Buenos Aires. Igualmente, resultó significativo que Posse vinculó a sus hijos con hijas de comerciantes locales, como fue el caso del matrimonio de Luis con Carmen Bores, descendiente de Don Francisco Bores. En este sentido, este enlace evidenció el proceso de unificación de las familias de españoles peninsulares en un período como la década de 1810 en donde se pusieron a prueba las estrategias y las capacidades de estas familias para afrontar un período que desde el punto de la participación política no les era favorable.

De la misma manera, los vínculos matrimoniales dan cuenta del capital social que poseía Manuel Posse, relacionado con una aceitada red comercial con su hermano Gerardo, de la cual participaban otros comerciantes como Pereira, Bores, Pondal y a la que se insertaron sus descendientes tras instalar sus pulperías en la ciudad de San Miguel de Tucumán. ${ }^{38}$ Aquí, se utilizó el concepto de capital social como los recursos asociativos que poseía Posse, relacionados con la organización de una red parental y asociativa desde el punto de vista comercial. ${ }^{39}$

Asimismo, se comprobó que estos vínculos sociales y familiares atemperaron el peso de la Revolución en el caso de Manuel Posse sindicado como el comerciante de origen peninsular de mayor capacidad de giro comercial en 1813. ${ }^{40}$ A pesar de ello, de los nueve empréstitos solicitados por las autoridades revolucionarias, sólo participó de cuatro aportando un total de 3015 pesos,

\footnotetext{
${ }^{37}$ Hernán Otero. "Una visión crítica de la endogamia: reflexiones a partir de una reconstrucción de familias francesas (Tandil, 1850-1914). Estudios Migratorios Latinoamericanos; año 5, agosto diciembre, no 15-16. Buenos Aires, 1994; págs. 521-548.

38 Posse constituyó una aceitada red mercantil con su hermano Gerardo, que concentró exportaciones desde la ciudad de Buenos Aires con destino Tucumán y de la que participaron otros comerciantes locales como Pereira, Pondal, Bores, entre otros. Véase: Francisco Bolsi. "Familia, estrategias de reproducción social y comercio de exportación en Tucumán, Argentina, 1780-1820. Una aproximación a partir de la familia Posse". Anuario de Estudios Americanos; ${ }^{\circ} 70$, enero - junio. Sevilla, 2013; págs. 129-156.

${ }^{39}$ Julio Cesar Rodríguez Treviño. "Cómo utilizar el análisis de redes sociales para temas de historia”. Signos Históricos; n² 29, enero-junio. México, 2013; pág.105.

40 Francisco Bolsi. "Familias de la elite, revolución y guerra. Una aproximación a partir del clan Posse en Tucumán, Argentina, 1810-1830". Secuencias, n 76, enero-abril. Michoacán, 2010; pág. 67.
} 


\section{Redes sociales, vínculos familiares y poder político}

ubicándolo entre los tres más grandes contribuyentes a la Revolución. Si bien Posse aportó una cantidad significativa, las autoridades no ejercieron una presión constante sobre el patrimonio económico del peninsular, que de acuerdo al censo de 1813 era de 60.000 pesos. Según lo observado, la fortaleza de los lazos sociales con miembros de la elite a partir del parentesco y el hecho de que la revolución no generó una división tajante entre peninsulares y criollos, fueron elementos que jugaron a favor de Posse. ${ }^{41}$

Sus descendientes contribuyeron en los empréstitos con cantidades menores debido a que recién se iniciaban en sus actividades comerciales e incluso dos de ellos participaron en las filas del ejército en la batalla de 1812 en el batallón de comerciantes. De la misma manera, ocuparon diferentes cargos en el Cabildo en el transcurso de la década revolucionaria. En 1814, José Víctor fue elegido Regidor Juez de Policía. ${ }^{42}$ En 1815, Francisco fue designado en un momento como Caballero Síndico Procurador de la ciudad y posteriormente, Regidor Llano Vocal de la Junta Municipal de Propios y Arbitrios y en 1816 Regidor Defensor General de Menores y Pobres. ${ }^{43}$ Por último en 1817, José Víctor fue elegido como Regidor de Fiestas y en 1819, Alcalde Ordinario de Segundo Voto. ${ }^{4}$

\section{La década de 1820 y el proceso de construcción de nuevas redes familiares y sociales}

A fines de la década revolucionaria los cuestionamientos de las provincias del interior hacia el Directorio de Rondeau provocaron un aumento de la tensión política entre los sectores federales y unitarios. Finalmente, la batalla de Cepeda puso fin al conflicto cuando las tropas de los caudillos federales Estanislao López (Santa Fe) y Francisco Ramírez (Entre Ríos) derrotaron al ejército unitario del Director Supremo. La culminación de este enfrentamiento generó la apertura de un nuevo proceso vinculado con las autonomías provinciales, caracterizado por un marcado constitucionalismo, experiencias republicanas y la ruralización del poder con el surgimiento del caudillismo, fenómeno analizado por Halperin Donghi en su celebré libro Revolución y Guerra. ${ }^{45}$

En el caso tucumano, en 1819 el ex - gobernador Bernabé Araóz organizó un levantamiento armado, destituyó al gobernador Mota Botello y asumió con anuencia del Cabildo de la ciudad, el cargo de gobernador interino. ${ }^{46}$ Poco después proclamó la constitución de la República del Tucumán, que anexó bajo su jurisdicción a la provincia de Santiago del Estero y a Catamarca. La existencia de

\footnotetext{
41 Irene García de Saltor. La construcción del espacio..., Op. Cit., pág. 52.

42 Celia Avellaneda de Ibarreche, María del Carmen Del C. Clessi y Jorge Corominas. "Autoridades del cabildo...", Op. Cit. pág. 196.

43 Ídem, pág. 197.

44 Ídem, pág. 198.

45 Tulio Halperin Donghi. Revolución y guerra. Formación de una elite dirigente en la Argentina criolla. Buenos Aires, Siglo XXI Editores, 2002.

46 Celia Avellaneda de Ibarreche, María del Carmen Del C. Clessi y Jorge Corominas. "Autoridades del cabildo...", Op. Cit. pág. 210.
} 


\section{Francisco Bolsi}

esta república fue efímera. Al poco tiempo de su organización, Santiago del Estero se separó bajo el liderazgo de Ibarra -caudillo local-y el mismo ejemplo siguió Catamarca. La desfavorable situación económica, la carencia de consenso político como líder de la república y los aprestos de invasiones militares procedentes de las provincias vecinas, generaron una revolución -dirigida por Javier González- que depuso a Araóz de sus funciones. A partir de estos sucesos, la provincia de Tucumán transitó entre pujas por el poder entre caudillos locales como Bernabé Araóz y Javier López hasta 1824.

En este contexto de confrontación, el enemigo ya no se encontraba afuera como en la época revolucionaria- sino que adentro, en donde las facciones locales se disputaban el poder. En este ámbito de inestabilidad política, en 1822 José Víctor Posse fue elegido gobernador a instancias de Javier López, quien se enfrentaba políticamente con Araóz. ${ }^{47}$ Sin embargo, las disputas por el poder entre estos dos jefes militares solo permitieron que Posse ejerciera funciones administrativas debido a que las amenazas de constantes levantamientos militares de una facción u otra condicionó su gobierno. Ante la imposibilidad de llevar a cabo su mandato renunció, aunque esto no significó su apartamiento de la función política. En 1824 fue elegido Síndico Procurador de la ciudad y posteriormente en 1828 fue designado Juez de primera instancia. ${ }^{48}$ El resto de la familia ocupó diversas funciones públicas, hecho que permitió que los Posse cimentaran las bases de su poder político en la década de 1820. Luis Posse fue elegido como Regidor de Fiestas en $1820^{49}$. Roque Pondal -esposo de María del Rosario Possedesempeñó el puesto de Regidor Decano en 1821, Alcalde Ordinario de Segundo Voto en 1822.50 Asimismo, en 1823 fue elegido Manuel Posse -iniciador del clan familiar- como Síndico Procurador, hecho significativo debido a que no desempeñaba ninguna función pública desde 1810 cuando los criollos detentaron los cargos en el Cabildo. ${ }^{51}$

En el ámbito económico, los Posse continuaron con sus actividades mercantiles transformándose Luis Posse en uno de los actores comerciales más significativos del entorno familiar. ${ }^{52}$ La red mercantil constituida por su padre y tío continúo funcionado, por este motivo, los descendientes de Posse se consolidaron en este espacio ante la retracción de Manuel Posse como principal actor comercial antes del inicio del proceso revolucionario.

Las rencillas políticas entre los jefes militares alteraron no sólo la dinámica de la elite en su conjunto sino la red social constituida por los Posse. Sin embargo, resultó significativo cómo los lazos de parentesco permitieron a José Víctor Posse alcanzar la gobernación, debido a que si bien era un hombre sin poder militar

\footnotetext{
47 Ídem, pág. 208.

48 Ídem, pág. 209.

49 Ídem, pág. 206

50 Ídem, págs. 207-208

51 Ídem, págs. 209

52 Francisco Bolsi. “Familias, estrategias de reproducción social...”, Op. Cit, pág. 150.
} 


\section{Redes sociales, vínculos familiares y poder político}

contaba con la venia de Bernabé Araóz, con quien lo unía un parentesco de segundo grado, a partir de su casamiento con Tomasa Pereira y Araóz.

\section{Conflictos intra elitarios y la familia Posse entre 1830-1850}

La década de 1820 culminó con el enfrentamiento entre unitarios y federales, quienes dirimieron sus fuerzas en la batalla de la ciudadela, inclinando la balanza hacia el sector federal. La asunción de Alejando Heredia como gobernador marcó la hegemonía federal en el norte y la alianza de este último con Rosas, líder de la Confederación.

La historiografía local indagó acerca del enfrentamiento entre unitarios y federales en el contexto local percibiendo que Alejandro Heredia no exacerbó el conflicto sino que intentó una política de fusión de partidos. ${ }^{53}$ De acuerdo con Iramain, a partir de los discursos de Alejandro Heredia es posible descubrir la construcción de una comunidad política que intentó dejar atrás las diferencias para poder sobrevivir, debido a que identificó al enemigo fuera de la provincia, hecho que conllevo a ubicar la guerra en el exterior de la provincia y no al interior de la sociedad tucumana. ${ }^{54}$

Sin embargo, esta política de fusión no fue aceptada por todos los miembros de la elite. Los Posse, que participaron a favor del sector unitario en la Liga del Interior, perdieron la posibilidad de asumir cargos en la Sala de Representantes. Sólo Luis Posse designado Juez de Segunda Denominación entre 1834-1838 participó de cargos públicos, debido a que el sector de la élite a favor de Heredia cerró todos los caminos para acceder al poder. ${ }^{55}$ Sin bien, el gobernador alentó la fusión de partidos, mantuvo a algunos integrantes de la élite al margen. Esta tensión se evidenció en la campaña tucumana, principalmente con familias que contaban con una clientela significativa como era el caso de los Posse. 56

Heredia implementó una serie de impuestos a partir de 1834 con la finalidad de recuperar las finanzas de la provincia que se encontraban extenuadas luego del conflicto suscitado por la Liga del Interior. Esta política impositiva se orientó a reactivar el comercio con el tradicional eje alto peruano promocionando rubros como el cultivo de la caña de azúcar, la ganadería y el procreo de mulas para el transporte. ${ }^{57}$ Estas medidas generaron controversias con el sector de

\footnotetext{
${ }^{53}$ Irene García de Saltor Irene. La construcción del espacio..., Op. Cit, págs. 123-124.

54 Pablo Iramain. La construcción de comunidades..., Op. Cit, pág. 282.

55 Actas de la Sala de Representantes (1939), sesión del 8-I-1834, Tucumán, Vol. II. (desde 1823 hasta 1852), pág. 305.

56 Heredia impuso un estricto control militar, sobre todo a aquellas familias que poseían una clientela significativa a partir de las actividades económicas que desarrollaban en la Reducción. En el caso de los Posse, luego de la conjura perdieron poder de movilización. Pablo, Iramain. La construcción de comunidades..., Op. Cit, pág. 286.

57 El propósito de Alejandro Heredia al diseñar esta política económica proteccionista tuvo la finalidad de mejorar la aletargada economía local, conformar un mercado interno de producción que permita el abastecimiento y una exportación sostenida, además vincular nuevamente a Tucumán, con el mercado altoperuano proveedor de metálico, hecho que evitaría un drenaje constante de recursos, debido a que el único mercado en donde Tucumán colocaba productos era
} 


\section{Francisco Bolsi}

comerciantes de orientación atlántica, que se manifestaron tanto a nivel institucional como militar. ${ }^{58}$ Esta situación motivo la reacción de un sector de la familia Posse, quienes mantenían su vinculación con el eje Tucumán - Buenos Aires desde fines del siglo XVIII.

Ese mismo año, la Sala de Representantes eligió nuevamente a Alejandro Heredia como gobernador por amplia mayoría, hecho que fortaleció aún más su poder político. ${ }^{59}$ Las medidas económicas y el férreo control de las milicias generaron el contexto propicio para que Ángel López -pariente del exiliado caudillo Javier López- instigara a algunos simpatizantes del unitarismo a conjurar una revuelta en contra de Heredia. Contó con el apoyo de varios comandantes de la campaña tucumana que ejercían el control en diferentes distritos como era el caso de Sorroza en Monteros, Colombres en el Colmenar y de algunos comerciantes como Gerónimo Helguera, Calixto Pérez y los hermanos Vicente y Felipe Posse. ${ }^{60}$ Estos últimos, contaban no sólo con recursos económicos sino con una clientela peones que trabajaban en la estancia la Reducción- y que eran movilizados de acuerdo a las necesidades de sus patrones. ${ }^{61}$ Finalmente el movimiento sedicioso fue descubierto por Heredia, que tomó prisioneros a los conspiradores condenándolos a la pena de muerte. Gracias a la intervención de dos abogados Juan Bautista Alberdi y Antonio Fragueiro- el gobernador perdonó la vida a los acusados pero les impuso el destierro. ${ }^{62}$

Buenos Aires. Norma Pavoni. El noroeste argentino en la época de Alejandro Heredia. Tucumán; Tomo II, Economía y Sociedad, Ediciones Fundación Banco Comercial del Norte, 1981; págs. 1-4. Asimismo véase: Paula Parolo. "La presión fiscal sobre el comercio tucumano en el siglo XIX". Revista de la Escuela de Historia, Vol. 1-2. Salta, 2011; págs. 109-131.

58 La Comisión de Hacienda encargada de analizar el proyecto de Heredia, estaba compuesta por comerciantes vinculados con la ruta comercial atlántica, motivo por el cuál, ofrecieron resistencia a la implementación de esta política impositiva. Esto evidenció un marcado perfil librecambista en contraposición con las intenciones proteccionistas del gobernador. Norma Pavoni. El noroeste argentino..., Op. Cit. pág. 9.

${ }^{59}$ Actas de la Sala de Representantes..., Op. Cit. págs. 511-512.

60 Se organizó una fuerza militar de 200 hombres, integrada en su mayoría por integrantes de la clientela de la familia Posse y Colombres. AHT, SA, f.302. De la misma manera, las relaciones entre los Colombres y los Posse no se regían simplemente por la afinidad política sino por lazos de parentesco a partir del casamiento de Juan Posse -hijo de Vicente- con Carmen Colombres. De acuerdo con Macias, esta conspiración quiso diferenciarse de una instancia de desorden que revivía el tradicional conflicto entre unitarios y federales. Por esto para justificar el levantamiento de acuso a Heredia de tirano, motivo por el cual, el pueblo asumía la vía armada para recuperar la soberanía. Flavia Macias, "Ciudadanos armados y fuerzas militares en la construcción republicana decimonónica". Identidad nacional hacia la Argentina del Bicentenario. Reflexiones sobre el concepto de ciudadanía. Buenos Aires, Honorable Senado de la Nación, 2009; pág. 11.

${ }^{61}$ En este trabajo, se tomó los conceptos vertidos por James Scott acerca de la clientela. En este sentido, se entiende por clientela a la relación patrón -cliente en donde existe una relación de intercambio de roles, que poseía un carácter instrumental, en donde el patrón utiliza su posición (socio - económica) para proveer protección o ciertos beneficios como el trabajo, a una persona que tiene un status social menor y que actúa de forma recíproca brindando apoyo y asistencia. En este sentido, se analizó a la clientela de los Posse, como los peones y trabajadores que estaban bajo su protección. James Scott. "Patronazgo o explotación”. Ernst Gellner. Patrones y clientes. Madrid, Jucar, 1987; págs. 35-61.

62 José María Posse. Los Posse..., Op. Cit., pág. 44. 


\section{Redes sociales, vínculos familiares y poder político}

Esta situación condicionó la participación política de los Posse en el ámbito local. Sin embargo continuaron sus actividades económicas dedicadas al comercio de exportación y a la compra de inmuebles en la ciudad y la campaña. ${ }^{63}$

El asesinato de Heredia en 1838 generó un vacío de poder que permitió el regreso de algunos emigrados y la puesta en funcionamiento del sector unitario. Los Posse participaron de la organización de la Liga del Norte, Vicente regresó a Tucumán luego de su destierro y cuando surgió este nuevo levantamiento unitario se unió a él inmediatamente. Su hermano Luis se involucró desde un principio debido a que formó parte de la comisión -junto con Manuel Paz y Brígido Silvaque aprobó el tratado ofensivo - defensivo en contra de la autoridad Rosas. ${ }^{64} \mathrm{La}$ empresa militar asumida por los integrantes de la Liga del Norte finalizó en una derrota a manos de las fuerzas federales del General Manuel Oribe en la batalla de Famaillá. 65 Esto determinó la suerte de las familias que participaron en la conformación de la Liga que fueron perseguidas y sufrieron el exilio de la provincia.66 Vicente Posse fue tomado prisionero pero finalmente logró salvar su vida. Su hermano Luis, en cambio, fue perseguido por las autoridades federales, circunstancia que lo obligó a exiliarse en Córdoba aunque no dispuso de sus bienes que fueron confiscados. Recién en 1844, durante el gobierno federal de Celedonio Gutiérrez, regresó a Tucumán. Por iniciativa del Ejecutivo se aprobó una amnistía con el propósito de culminar las luchas intra elitarias con las familias comprometidas con el unitarismo y de esta manera, pacificar definitivamente la provincia.

Los Posse a partir de la derrota de la Liga no volvieron a organizarse nuevamente en contra del gobierno de Celedonio Gutiérrez. ${ }^{67}$ Sin embargo, estas dos décadas evidenciaron el comportamiento interno de la familia, en donde existió una asignación de roles entre los hermanos. En este sentido, Simón, José Víctor y Francisco fueron los encargados de sostener la red comercial con Buenos Aires, como así también representar en la medida de lo posible a la familia en el ámbito político local. Vicente y Felipe fueron los que participaron en las sublevaciones e intentaron romper con la hegemonía de las familias que representaban al sector federal. Sin embargo, se fueron perfilando nuevos actores

\footnotetext{
63 AHT, Sección Comprobantes de contaduría, período 1830-1840. Sección Protocolos, Serie A, 1832, $\mathrm{f}$.

64 Actas de la Sala de Representantes (1939), sesión del 16-X-1841, tomo II (desde 1823-hasta 1852), UNT, págs. 320.

65 Carlos Páez de la Torre. Historia de Tucumán. Buenos Aires, Editorial Plus Ultra, 1986, págs. 432.

66 De este movimiento sedicioso participó también Wenceslao Posse, quien había emigrado en 1824

a Buenos Aires. Wenceslao participó del levantamiento de los Libres del Sur con Rosas y tras la derrota de este pronunciamiento se ocultó hasta que con ayuda del Gral. Lamadrid llegó a Tucumán e integró el ejército unitario de la Liga bajo el mando de Lamadrid. Jorge Gelman. "La rebelión de los estancieros contra Rosas. Algunas reflexiones en torno a los libres del sur". Entrepasados; n²2. Buenos Aires; pág. 118.

67 Los Posse no conspiraron nuevamente contra el gobierno federal de Gutiérrez hasta la caída del rosismo. Por este motivo, centraron su atención en sus actividades comerciales y la compra de inmuebles en la ciudad. El casamiento de Colombres con la única hija de Gutiérrez marcó el inicio de la pacificación de la provincia.
} 


\section{Francisco Bolsi}

en la red de parentesco que proporcionarían a la familia una nueva dinámica a partir de la década de 1850, como fue la figura de José Posse -hijo de Simón Posse y Josefa Insúa y García- y la rama de los Posse Talavera, hijos de Vicente, quien fue el miembro de la familia que mayor cantidad de descendientes tuvo y que dinamizaron la red social y familiar.

En cuanto a la red social, resulta significativo que los Posse siempre actuaron a partir de las movilizaciones de los jefes militares que tuvieron incidencia en esos conflictos. En este sentido, la red social se conformaba en un momento determinado y tenía existencia efímera, debido a que luego de cada uno de los fracasados pronunciamientos esta red de lealtades personales en torno a Ángel López en un primer momento y con el Gral. Lamadrid en un segundo momento, se disolvieron. Del mismo modo, esta situación dio cuenta de la capacidad de Heredia como de Gutiérrez de sostener una red de lealtades personales a partir de la organización del ejército y de favores personales que les permitieron conjurar los pronunciamientos y sostenerse en el poder. ${ }^{68}$

\section{El contexto tucumano y el accionar de la segunda generación de los Posse entre 1850-1870}

La pronunciamiento de Urquiza en 1851 abrió nuevamente el camino de la confrontación y la recuperación de la legalidad confederal preexistente, definida en el Pacto Federal de 1831. El éxito de Urquiza en Caseros en 1852 obligó a las provincias del interior a tomar una postura frente al nuevo poder que emergía desde Entre Ríos.

En el ámbito provincial, Gutiérrez concurrió a San Nicolás, momento que fue utilizado por la elite para desplazarlo del gobierno. El diputado Salustiano Zavalía junto a José Posse presentó un proyecto de ley que duplicaba la representación en la Sala de Representantes. ${ }^{69}$ Luego de la aprobación de esta ley, la oposición consiguió la mayoría en la Sala y destituyó a Gutiérrez. ${ }^{70}$ A pesar de los esfuerzos de Gutiérrez por recuperar el poder, el cura José María Del Campo, lo derrotó en la batalla de los Laureles y asumió el poder en 1853.

La gobernación de Del Campo fue la plataforma propicia para la consolidación de los Posse en el ámbito local. Esta familia apoyó económicamente a las tropas que el cura dirigió para enfrentar a Gutiérrez. ${ }^{71}$ El resultado de este

\footnotetext{
${ }^{68}$ Esta temática fue estudiada por la historiografía local, destacándose los aportes de Macías y Parolo. Véase: Flavia Macías. "El servicio de armas ciudadano. Ejército provincial y cuerpos cívicos en Tucumán - Argentina en tiempos de la Confederación Rosista". Revista Rábida de Ciencias Sociales. Huelva, 2008; págs. 30-42. Flavia Macías y Paula Parolo. "Guerra de independencia y reordenamiento social. La militarización en el norte argentino (primera mitad del siglo XIX)". Iberoamericana; Vol. 37. Berlín, 2010; págs. 20-38.

${ }^{69}$ Manuel Posse se desempeñaba como diputado por el departamento capital, mientras que Luis y José Posse representaban al departamento de Monteros, territorio en el que poseían extensas propiedades y clientela. Actas de la Sala de Representantes...., Vol. II..., Op. Cit. págs. 31, 291 y 404.

${ }^{70}$ Actas de la Sala de Representantes, Vol. II..., Op. Cit., pág. 348.

${ }^{71}$ José María Posse, Los Posse..., Op. Cit.
} 


\section{Redes sociales, vínculos familiares y poder político}

enfrentamiento marcó el triunfo de los liberales en el contexto político tucumano y la reorganización total del elenco de gobierno. No obstante las fugaces alianzas, los intereses contrapuestos de las familias que conformaron el partido liberal y la necesidad de establecer una postura respecto al gobierno nacional generaron la división de este grupo. Mientras un sector era partidario de la fusión con la política de Urquiza, el otro tenía una posición sumamente crítica hacia el presidente de la Confederación. Los Posse se manifestaron en contra de la postura de fusión porque estaba alineado políticamente con la fracción liberal de Sarmiento.

En 1854 fue elegido gobernador Del Campo y rápidamente tuvo que desarticular las alianzas militares del depuesto Gutiérrez. Por este motivo, organizó dos batallones de Guardias nacionales en el departamento Capital y Monteros. ${ }^{72}$ Asimismo, recibió el apoyo de los Posse que contaban con una red familiar que poseía trapiches azucareros en cercanías de la ciudad, la Reducción y Monteros, se dedicaba al comercio -actividad heredada del fundador del clan- y a la cría de ganado en el departamento de Trancas. ${ }^{73}$ Esta diversificación económica -era propia de la elite de este momento- se relacionó con la ductilidad del sector comercial para reinvertir en actividades agrícolas y manufactureras los excedentes acumulados en la intermediación comercial. ${ }^{74}$

El gobernador Del Campo eligió a José Posse como Ministro General de Gobierno, hecho que generó una mayor fragmentación en el partido liberal, debido a que la figura de José era resistida por una parte de la elite representada por los Zavalía y los Frías, estos últimos conectados políticamente con los hermanos Taboada de Santiago del Estero. Posse durante su efímero mandato como Ministro mostró una postura contraria al gobierno nacional y de carácter personalista, motivo por el cual, las presiones políticas desde la Sala de Representantes obligaron a Del Campo a pedirle la renuncia a Posse..$^{75}$ A partir de esta situación, los Posse articularon su red de parentesco en torno a dos ramas familiares que fueron los Posse Insúa y los Posse Talavera. A los primeros, pertenecía José "Pepe" Posse, quien se transformó en el actor central de la red social y política de la fracción liberal que estaba en contra del mandato de Urquiza, y contó con el apoyo de Wenceslao, Ciriaco, Manuel, Emidio, Benjamín y Ramón por parte de los Posse Talavera, que poseían una clientela significativa en los departamentos de Lules y Monteros y posteriormente fueron elegidos comandantes de campaña por Regimiento de los Cívicos.

La elección a gobernador en 1856 enfrentó a dos candidatos del partido liberal, Anselmo Rojo partidario de la fusión con el emergente gobierno nacional y José Posse con una postura totalmente contraria. Finalmente, el día de la elección un sector de la familia Posse que se encontraba armada presionó a la Sala de

\footnotetext{
72 Esta situación generó diferencias con el cuerpo de Cívicos que participó activamente en el derrocamiento de Gutiérrez. Flavia Macias. "Ciudadanos armados...", Op. Cit., pág. 57.

73 Francisco Bolsi. Azúcar, Familia, Parentesco y Poder Político en Tucumán, Argentina. Un estudio comparado de las familias Posse y Nougués (1830-1930). Saarbrücken, EAE, 2012; pág. 26.

${ }^{74}$ María Celia Bravo y Daniel Campi. “Elite y poder en Tucumán...” Op. Cit., págs. 81-82.

75 María Celia Bravo. “La política “armada” en el norte argentino....”, Op.Cit. pág. 250.
} 


\section{Francisco Bolsi}

Representantes para que eligiera a José como gobernador, pero fueron expulsados y la elección se volcó a favor de Rojo. ${ }^{76}$ Esto provocó la reacción de los Posse que realizaron un movimiento armado conocido en la historiografía local como la revolución de los Posse. ${ }^{77}$ Esta sublevación organizada por Del Campo fracasó y provocó el exilio de este último y de varios miembros de la familia que emigraron a Santiago del Estero. El resto, sobre todo los integrantes de la rama Posse Talavera, hicieron demostraciones de fuerza que conllevaron a una tensión con el comandante de la zona Miguel Padilla. ${ }^{78}$

En la década de 1860, la situación política nacional resultó favorable para que los Posse regresen a la escena local a disputar el poder. Del Campo fue elegido nuevamente gobernador en $1862 .{ }^{79} \mathrm{El}$ mecanismo de lealtad y amistad política que unía al primer mandatario y a los Posse se puso en funcionamiento. Por este motivo, fue elegido Arsenio Granillo -unido a los Posse Talavera tras su casamiento con Sabina- como Ministro General y José Posse como diputado nacional. ${ }^{80}$ En 1864, José Posse accedió a la gobernación, hecho que marcó un uso exclusivo de la política, del control legislativo y de las comandancias de los batallones de la Guardia Nacional, espacio conquistado durante el mandato de Del Campo un par de años antes. ${ }^{81}$ En 1866 fue electo Wenceslao Posse como gobernador, lo que marcó la continuidad del clan en el poder. ${ }^{82}$ Los integrantes de la familia alcanzaron representación nacional a partir de la elección como diputado de Filemón Posse en 1864 y de senador de Manuel Posse en 1866.83 En el medio local, fueron elegidos como electores provinciales: Manuel Posse (1860-64), Emidio Posse (1865), Juan Posse (1866), Roque Pondal Posse (1862-65), Tiburcio Molina (1863-65-67). ${ }^{84}$

Asimismo, la red de parentesco tuvo una fuerte representación con la incorporación de Arcadio Talavera, Arsenio Granillo, Benigno Vallejo, Roque Pondal, Juan Del Campo y Silvestre del Campo -sobrino y hermano del ex

\footnotetext{
${ }^{76}$ Rojo luego de ser elegido, desarticuló las bases de poder de movilización de la familia Posse, quitándole la comandancia a Benjamín Posse de Monteros pero no consiguió relevar a los comandantes José Ciriaco y Ramón Posse, que eran hombres fuertes de la Reducción y Lules. Florencia Gutiérrez. Las prácticas políticas en Tucumán en la década de 1860. El partido Posse (Tucumán), 1997; pág. 8.

77 Flavia Macías, y María José Navajas. "Entre la violencia y la institucionalización provincial. La revolución de los Posse en Tucumán, 1856". Boletín del Ravignani. Buenos Aires, 2013.

78 María Celia, Bravo, "La política "armada" en el norte argentino..." Op. Cit, pág. 253.

${ }^{79}$ Actas de la Sala de Representantes (1939), 14 de junio de 1852, UNT, Tucumán, Vol. III (18621867), pág. 175.

80 Carlos Cordeiro y Dalmiro Viales. Compilación ordenada de leyes, decretos y mensajes del período constitucional que comienza en el año 1852, Vol. III (1862-1867). Tucumán, 1815; pág. 44.

${ }^{81}$ Flavia Macías. “Ciudadanos armados...", Op. Cit., págs. 24-25.

${ }^{82}$ AHT, SA, 1866, f. 35.

${ }^{83}$ Diario de Sesiones de la Cámara de Diputados del Congreso de la Nación, 1864, pág. 3, 1866.

${ }^{84}$ Carlos Cordeiro y Dalmiro Viales. Compilación ordenada de leyes..., Op. Cit, pág 44. Tiburcio Molina, era un actor político que actuaba en la red de los Posse.
} 


\section{Redes sociales, vínculos familiares y poder político}

gobernador José María Del Campo- quienes fueron diputados provinciales en la legislatura local ${ }^{85}$.

En este sentido, al analizar la red social de los Posse, se evidencia el rol central que jugó José Posse, amigo personal y aliado político de Sarmiento, quien fue el responsable de asignar los roles en el interior de la red. Los miembros de la rama de los Posse Talavera acompañaron este proceso, hecho que redundó en un acrecentamiento del patrimonio familiar a partir de la adquisición de propiedades en la campaña y la ciudad por diversas sociedades como fueron Posse Felipe y Pondal Roque; Felipe Posse y Cía. y Wenceslao Posse en la zona de Cruz Alta, en donde funcionaba su ingenio, el Esperanza. ${ }^{86}$

El manejo exclusivista de la política local generó la división del partido liberal en dos facciones, cuyas diferencias se agudizaron al momento de la sucesión presidencial. Por un lado, la fracción possista (club Sarmiento) que propugnaba la candidatura presidencial de Sarmiento, por otro lado, el denominado Club del Pueblo, que sostenía la de Rufino Elizalde (candidato de Mitre) y era apoyada por los Taboada. ${ }^{87}$ Con el sustento del clan santiagueño y liderado por Octaviano Luna, los integrantes del Club del Pueblo, derrocaron a Wenceslao Posse. Ante las circunstancias desventajosas que se le presentaron no tuvo otra opción que presentar su renuncia ante la Sala de Representantes y de esta manera evitó un derramamiento de sangre. El único integrante de la familia, que reaccionó ante la marcha de los acontecimientos, fue Emidio Posse, pero Wenceslao ante el mayor poder de fuego de la Guardia Nacional y la superioridad de fuerzas en relación con las tropas de cívicos movilizadas por su hermano, el gobernador depuesto, le solicito a su hermano que desistiera de sublevarse. ${ }^{88}$

En este sentido, la política exclusivista de los Posse, el marcado nepotismo en la designación de los cargos públicos y su postura política contraria a los deseos de Mitre generaron su derrocamiento por parte de los Taboada, asociados con jefes militares locales pertenecientes a la Guardia Nacional. Este hecho marcó, un hito en la historia familiar debido a que recién en 1886 lograron acceder al poder ejecutivo.

\section{Conclusiones}

\footnotetext{
85 Arcadio Talavera y Olivera, era hermano de la esposa de Vicente Posse -Sabina Talavera y Olivera-. Arsenio Granillo de la Colina se casó con Sabina Posse Talavera y Benigno Vallejo contrajo matrimonio con Nicéfora Posse Talavera, ambas hijas de Vicente Posse. Francisco, Bolsi. Azúcar, empresarios..., Op. Cit, pág. 251.

86 AHT, Sección Protocolos, Serie A, 1865 f. 167 (v), f. 456; 1866 f. 9 (v), f. 60 (v), f. 174. Serie B, 1862, f. 41; 1863, f. 16; 1864, f. 34. Serie C, 1868, f. 63 y f. 64. Serie D, f. 71, f. 120, 1869, f. 26, f. 58, f. 72, f. 105, f. 108.

87 Florencia Gutiérrez. Las prácticas políticas...., Op. Cit. pág. 43.

88 Flavia, Macías. "Ciudadanía armada, identidad nacional y Estado provincial. Tucumán, 1854 1870". Hilda Sábato y Alberto Lettieri (comp.). La vida política en la Argentina del siglo XIX. Armas, votos y voces. Buenos Aires, FCE; pág. 243.
} 


\section{Francisco Bolsi}

El concepto de redes sociales resultó significativo al momento de indagar el caso de los Posse debido a que se analizó una familia, a partir de un estudio específico, la rotación de los actores que integraban la red de parentesco y como esta estructura tenía una representación no sólo económica, sino también política y social.

En este sentido, se apreció que la dinámica familiar en sus inicios, a partir del establecimiento de Manuel Posse constituyó una red ego centrada que vinculó a esta familia con comerciantes -Pereira, Bores, Pondal- con una capacidad de giro comercial significativa. De la misma manera, se observó cómo prevalecieron los lazos de solidaridad entre comerciantes españoles peninsulares, lo que constituyó una práctica fuertemente endogámica entre actores sociales que tenían un mismo lugar de origen.

Paralelamente, se analizó cómo esos vínculos previos fueron esenciales al momento de atravesar la década revolucionaria, ya que a pesar de que Manuel Posse era el comerciante peninsular de mayor capacidad de giro mercantil en 1813, consiguió evitar el peso de las contribuciones forzosas solicitadas. En este sentido, se piensa que la fortaleza de los vínculos constituidos por Posse que sellaron acuerdos económicos, se transformaron en cuestiones mediadas por el parentesco a partir de las uniones matrimoniales que entrelazaron actividades mercantiles y vínculos familiares entre connacionales. Las relaciones fueron diádicas y se establecieron entre pares, es decir entre actores sociales que detentaban un prestigio simbólico y un capital económico significativo.

En cuanto a los integrantes de la primera generación, resultó interesante analizar la asignación de roles entre los hermanos, debido a que algunos conspiraron mientras que otros se mantuvieron al margen. Esto hizo referencia a como las obligaciones familiares generaron fuertes lazos parentales entre los miembros de la red de parentesco. La segunda generación denota una ampliación de la red de parentesco y de relaciones sociales. Sin embargo, son los Posse Insúa y los Posse Talavera, quienes se destacaron entre el resto de los integrantes de la familia objeto de estudio.

Una característica en ambas, es el poder de movilización de una clientela significativa y que dan cuenta de la influencia territorial de los Posse en los departamentos de Monteros y Lules, como así también la localidad de la Reducción. Este poder de movilización conllevó a su participación en dos ocasiones por el sector unitario y posteriormente, en la organización de una sublevación denominada en la revolución de los Posse. En este sentido, esta construcción territorial del poder sugirió nuevos interrogantes, al respecto de cómo reclutaban su clientela, quienes eran los intermediarios (brokers en la teoría de las redes sociales) que facilitaban los lazos con los actores sociales que estaban bajo su control, hecho que alienta profundizar aún más en el estudio de esta familia.

Asimismo, estas confrontaciones generaron un cambio paulatino de las estrategias familiares, con una ampliación de los vínculos parentales con uniones matrimoniales que excedieron el marco local y regional y apuntaron a su 
incorporación en la elite liberal que se conformó a partir de 1853. Este nuevo contexto político visibilizó relaciones diádicas entre la figura de José Posse y Sarmiento, quienes configuraron junto a otros actores políticos una red social que representó el proyecto político del sanjuanino. En el ámbito local, José Posse se transformó en el líder de la red social y parental, el cuál dominó la escena y marcó la asignación de roles de los integrantes de la familia durante la década de 1860, que fue cuando detentaron el poder. Estos vínculos fueron no sólo familiares, sino políticos debido a que los Posse orientaron sus estrategias con el propósito de implementar una política exclusivista, que posteriormente provocó su relegamiento hasta 1886 del centro de la escena provincial.

Recibido: 03/10/2015

Evaluado: $30 / 10 / 2015$

Versión Final: 04/12/2015 